\title{
EMon: Embodied Monitorization
}

\author{
Davide Carneiro ${ }^{1}$, Paulo Novais ${ }^{1}$, Ricardo Costa $^{2}$, Pedro Gomes ${ }^{1}$, \\ José Neves ${ }^{1}$ \\ ${ }^{1}$ DI-CCTC, University of Minho, Braga, Portugal \\ \{dcarneiro,pjon,jneves\}@di.uminho.pt,pg12890@alunos.uminho.pt \\ ${ }^{2}$ College of Management and Technology - Polytechnic of Porto, Felgueiras, Portugal \\ rfc@estgf.ipp.pt
}

\begin{abstract}
The amount of seniors in need of constant care is rapidly rising: an evident consequence of population ageing. There are already some monitorization environments which aim to monitor these persons while they remain at home. This, however, although better than delocalizing the elder to some kind of institution, may not still be the ideal solution, as it forces them to stay inside the home more than they wished, as going out means lack of accompaniment and a consequent sensation of fear. In this paper we propose EMon: a monitorization device small enough to be worn by its users, although powerful enough to provide the higher level monitorization systems with vital information about the user and the environment around him. We hope to allow the representation of an intelligent environment to move with its users, instead of being static, mandatorily associated to a single physical location. The first prototype of EMon, as presented in this paper, provides environmental data as well as GPS coordinates and pictures that are useful to describe the context of its user.
\end{abstract}

Keywords: Ambient Intelligence, Monitorization, Mobility, Portable Monitorization, Wearable Computers, Pervasive Computing

\section{Introduction}

Population ageing is a problem that nowadays affects almost every country in the world. According to its definition [1], population ageing is a shift in the distribution of a country's population towards greater ages. However, population ageing means much more as there are both social and economical costs associated to this problem that cannot be ignored [2]. According to a report prepared by the United Nations [3], the number of older persons has tripled over the last 50 years and will more than triple again over the next 50 years.

These seniors frequently have special needs and require a close and personalized monitoring, mainly due to health related issues [4]. The most common answers are the elder moving to a relative's house or to a senior institution. The first option generally carries major changes to the routine of the host family and not all families are willing to or able to carry that burden. The second one carries increasing economical costs 
which not every family member is able to support, neither is it a good option for the elder, since they usually show reluctance when being moved out from their normal habitat where they have their life [5], their friends and their routine. It is desired that older people can age and maintain their well being while dealing with all the diseases and limitations that arise, for as long as possible.

New approaches have therefore to be devised for dealing with this problem. The answer, in our opinion, relies on the coming together of a group of fields such as Artificial Intelligence techniques, Human-computer interaction, ubiquitous computing, sensors and network technologies. By merging insights from these fields of research, it is possible to build the so-called Intelligent Environments. These environments are able to sense their users and their surroundings, analyze the information gathered and take actions with the objective of increasing the security and well-being of the persons in the environment. In this context of aged population, the advantages of these environments can be even more deeply exploited, acting as a way of increasing the autonomy and independence of seniors, especially the ones living alone [6].

\subsection{The VirtualECare project}

The VirtualECare project [7, 8] aims at a Multi-agent based architecture in support of computational systems that seek to monitor and provide personalized health care services to its users or patients. These systems will interconnect healthcare institutions, leisure centres, patients and their relatives, on a common network, i.e., the VirtualECare architecture stands for a distributed one with its different nodes corresponding to a different role, either in terms of a call centre, a group decision support system or a monitoring device, just to name a few.

The nodes of the architecture depicted in the previous picture have been object of the work of this research team. However, in the ambit of this paper, we want to focus on the Supported User (Figure 1). This node of the architecture represents the person in need of care and is, therefore, constantly monitored inside his environment. We want, however, to extend this Monitorization to outdoor settings, following the person on-the-move, enriching the VirtualECare with this important feature. The work done in implementing this feature is described in this paper.

\subsection{Ambient Assisted Living in Healthcare}

Ambient Assisted Living (AAL) is a sub field of application of Ambient Intelligence. It builds on recent developments of IT and aims to promote the advantages that these technologies can have when put to work together to proactively assist their users in the day-to-day activities. Such a technology is able to lighten common and routine tasks, or even to replace their users in their execution. If to a regular user this means more comfort or free time to be spent in other activities, to senior or impaired users an assisted environment may mean autonomy, independence and security.

Indeed, these environments have known a significant growth in their use in the domain of the healthcare provision. At the MIT research has recently begun on the 
possibilities of AAL environments in the monitorization of patients in rural areas, that cover most of the territory of the countries but whose inhabitants generally lack access to health care [9]. We can also mention the Living Lab for Ambient Assisted Living in the Municipality of Schwechat that is a space where people from the community join together and share ideas and visions to implement technologies that support the independent living of seniors [10]. Another example is ALZ-MAS 2.0 which is an Ambient Intelligence based multi-agent system aimed at enhancing the assistance and health care for Alzheimer patients living in geriatric residences [11].

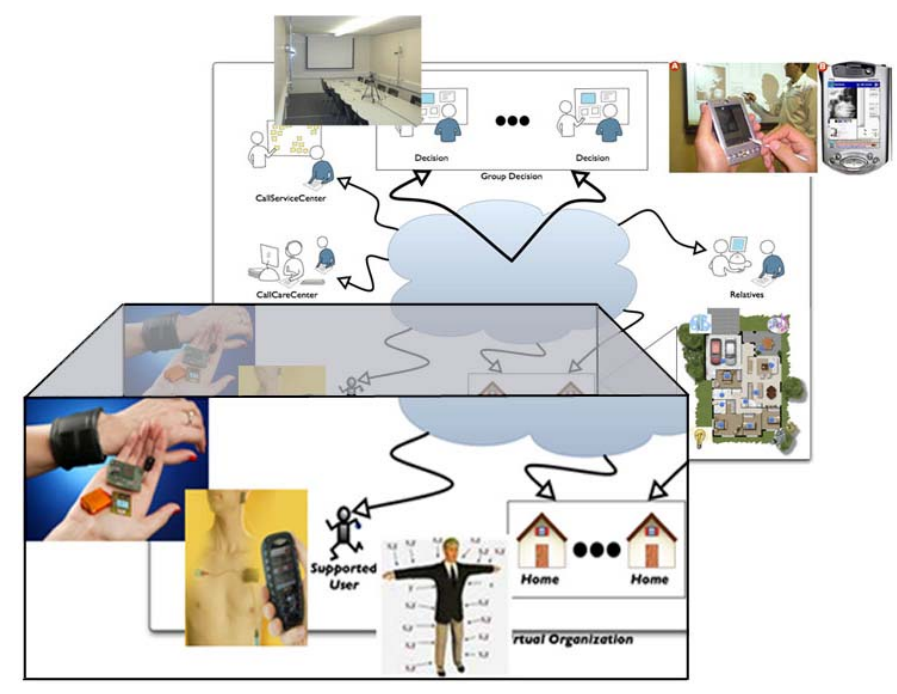

Fig. 1. The VirtualECare architecture, highlighting the components addressed in this paper.

AAL-based projects can result in the direct benefit of both caregivers and patients. For caregivers, it may represent a more efficient time schedule, the automation of determinate tasks, or a more close and constant contact with their patients. For the patients, an AAL environment may be synonym for a supportive system that constantly monitors them and proactively takes actions that ensure their safety. More than that, these environments can take care of the supervision of the house, ordering goods, controlling the temperature and humidity of the air or the access of other persons. These environments constitute therefore an important improvement to the healthcare delivery sector, being only bound by the restriction of being physically associated to a place. In this paper we intend to take the first steps to create mobile assistive environments that follow their users while they move.

\section{Embodied Monitorization}

In the ambit of the VirtualECare project, this team has developed a monitorization platform intended to monitor seniors in their environment [12]. This platform is 
placed in the Home component of the architecture visible in Fig. 1. It is responsible for collecting all the information about the environment considered important for the well being of the user, study the behaviour of the user in terms of the management of the house and infer rules for that management that are then applied by the system in an attempt to adapt the house settings according to the user's preferences [13]. In a few words, this monitorization platform helps to describe the context of the user. The information collected may comprise the temperature, luminosity or humidity of the several rooms of the user's house, the position of the user inside the house, the persons visiting or the state of the several appliances. Some reactive and simple decisions can be taken by the house when some predetermined events occur (e.g. turn on air conditioning when the temperature is high). Moreover, the information about the environment may also be shared with the higher level components of the architecture, namely the Group Decision, so that more complex or important decisions can be taken. More than that, the specialized staff has constant and updated information about the user context. When the environment around the user, by some reason, is not safe or recommendable, the system may react quickly by acting on the house actuators, by notifying the user or by any other measure.

This has however a great limitation: the user can only be monitored while he is inside the environment. The system stops receiving vital information about the user the moment he steps out of the house. This may, obviously, represent a risk, mainly when we talk of users who suffer from diseases that imply a constant accompaniment. The will to monitor the user independently of his location drove us to idealize EMon.

EMon has as objective to make monitorization so portable that it may, eventually, be worn by the user the same way he wears a watch or a necklace. With such a device, the user can be accompanied while he is on the move, increasing his selfassurance, autonomy and security. Although there are already some devices in the market with the objective of monitoring their users while they move, none of them provides a complete and integrated solution. Some are simple GPS-based locators while others monitor one or some vital signs.

What we propose is an integrated device that can provide a full range of important information to describe the context of the user and make it so small that it can comfortably be carried by its users. What we expect to achieve is that intelligent environments are no longer static environments, mandatorily associated to a single physical location, but can instead move while their users move, following them wherever they go.

We do not believe that a device for such a purpose is possible to develop at the present since, although the devices necessary become smaller every day, they still too big to be integrated in a single device that can be comfortably worn. We however believe that the concept can be proved to be valid by means of a working prototype, and its usefulness demonstrated through positive changes in the routines of seniors that wore them.

\subsection{Devices and Features}

In order to implement the prototype of EMon we initially had to consider which functionalities to implement. One of the more important features nowadays and the 
first one to be considered by us given the domain of the problem is the location. If the system has information in real time about the location of the senior, help can immediately be sent in case of an emergency. Moreover, location-based services can be provided to the senior such as suggesting nearby interesting places according to the preferences or providing directions to the closest health facility if not feeling well. Another important feature would be to inform the senior about nearby friends, relatives or persons in the same situation, with the same interests with whom he eventually would like to interact. Adding to this the common functionalities of location based systems like guiding a person to a specific place or saving favourite places in a list, we obtain a very complete solution that can be advantageous for any senior and especially for seniors suffering from conditions like Alzheimer's disease.

In order to implement these features, we are using a PDA's Global Positioning System (GPS) integrated module together with software developed to implement some of the said features. The software is responsible for constantly reading the NMEA strings from the GPS receiver and provide them to the system. Among the functionalities implemented by this software, we can mention the record of the path travelled by the senior, the current position or the smallest path to walk to a predetermined location (Fig. 2. The output file from the GetPathTo service visualized on Google Maps. In this case the client is in University of Minho and wants to go to the nearest hospital in the database which is located at lat: 41.547407, lon: 8.423090.). All these functionalities are implemented using Google Maps and Google Earth API.

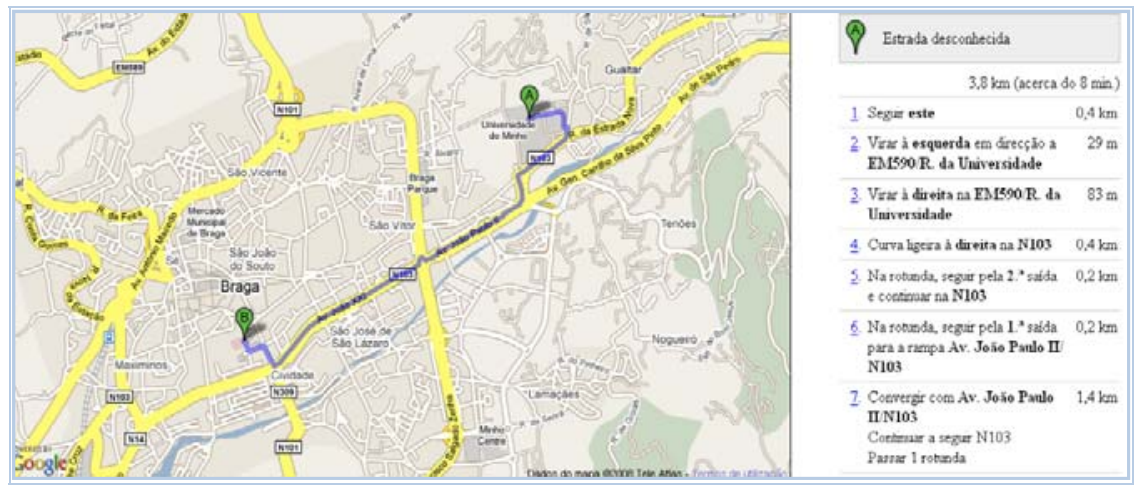

Fig. 2. The output file from the GetPathTo service visualized on Google Maps. In this case the client is in University of Minho and wants to go to the nearest hospital in the database which is located at lat: 41.547407, lon: -8.423090.

An important factor that conditions the health of the elder is the quality of the environment around him. This quality may be given in terms of factors like airborne pollutants, the humidity or the temperature. Our conviction that the monitorization of the environment around the elder is mandatory for ensuring his safety and well being is also shared by [14].

The importance of the air quality is even higher when we talk of seniors with diseases like asthma, bronchitis or cancer [15]. Having this in mind, we decided to incorporate into the prototype sensors which could provide the system with some 
information about the environment. Our purpose is that the system is able to warn the user if he is in a place where the environment is not safe or recommendable, according to his conditions. We have therefore decided to enrich the first prototype with temperature and luminosity sensors, embedded in the sleeve of the elder's jacket (Fig. 3). If, in one hand, the sensors chosen for the prototype are not of major importance as our objective in this first stage of the work is to present a proof of concept and test the architecture defined, in the other hand temperature and luminosity are two of the parameters that more influence our well being.

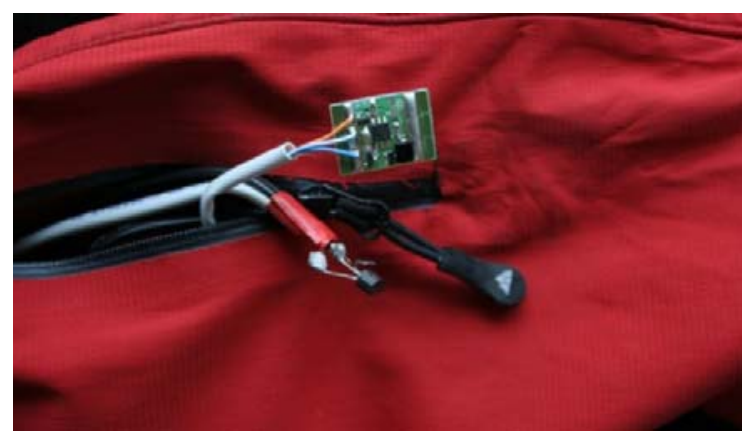

Fig. 3. The sensors embedded in the sleeve of the elder's jacket.

The last device added to the prototype of EMon was a webcam. The webcam has several purposes. In one hand, we verified that the GPS system is not always accurate in an urban environment, especially when used around obstacles that can prevent the signal to be received in the best conditions (e.g. high trees, buildings). The image provided by the webcam can therefore help to determine the exact location of the elder in case of need, acting as a complement to the GPS module. An example of application could consist in a medical team that is being sent to the location of the elder in need but whose GPS coordinates are not precise. Using the image, the medical team could locate the elder more precisely by looking at nearby buildings, landmarks or monuments. This image can be requested by the elder if he feels threatened or endangered or can be remotely taken by the system, if some predetermined event occur (e.g. a sudden rise in the heartbeat). The elder can also request a picture of something he likes and save it, like a common photo.

\subsection{A Service Based Architecture}

The architecture for implementing such a prototype has some specific issues. First of all, it must be a portable architecture as it will be traveling with the user. It must provide a constant connection to some network (e.g. Wi-Fi, GPRS, GSM, UMTS, HSDPA) so that the data gathered by the devices is constantly being routed to the higher level VirtualECare components. The architecture must also accept very different devices or components and provide means for their intercommunication. It should be dynamic and expansible, ready to accept new functionalities as we expect to continue adding new devices. Last but not the least, the architecture must be 
lightweight so that it may be implemented in portable, low battery-consuming devices.

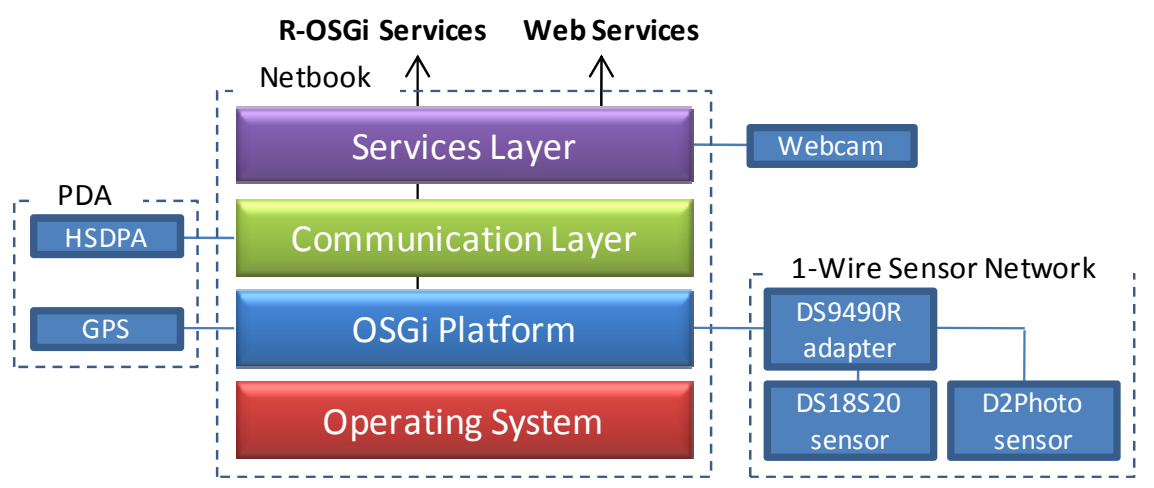

Fig. 4. The architecture of EMon.

We decided to base our architecture on two open service-oriented standards: OSGi [16] and Web Services. OSGi is a standard designed to promote the interoperability of applications and services over networks. It allows for java programs to be encapsulated into OSGi bundles, which are modules able of providing and using services of other bundles. The result is a modular way of building applications based on the junction of bundles, being the expansion of the application as easy as adding new bundles. For accessing and providing remote services, an extension to OSGi is used: R-OSGi. Web Services can be seen simplistically as a way of sharing information over a network. Each component that provides information declares Web Services that are then requested by the other components which need to access that information.

These two technologies are the base of our architecture. With this base, we gain interoperability and platform independence. This means that services can be used by any member of the VirtualECare architecture, independently of the platform or the device providing them. This also means that EMon can be used by any other higher level architecture similar to VirtualECare and use services provided by that architecture, therefore sharing advantages. It also results in a very expansible architecture as it is easy to add new components, which does not affect the components already present.

Let us now describe in more detail each component of the current EMon prototype and its place in the architecture (Fig. 4). The Netbook is the central core of our architecture. It provides support to all the other modules and is responsible for running the OSGi platform and the web services as well as for connecting all the devices. The OSGi platform being used is the Knopflerfish OSGi, an open source OSGi service platform. Two of the bundles running in this platform are the GPS and the 1Wire bundles. The first one is responsible for constantly reading NMEA strings from the PDA and parse them. The second one regularly reads the values of the sensors. These two bundles provide as services the values read so that other bundles can have easy access to that information. In the case of the sensor values, they are simply sent to the VirtualECare platform. As for the values of the GPS bundle, they 
can be used for three main purposes: the getPathTo service uses it to obtain the current position of the user and, through the Google Maps API, calculates a walking path to the destination provided by the user; the getLastValidLocation service simply provides the value of the last valid location of the user in the form of a Location object, a java object that encodes the latitude and longitude of the user; the getRecordedPath service returns the path of the user since the last time it was restarted. The getRecordedPath service generates a KML file that can be visualized on Google Earth while the getLastValidLocation and the getPathTo generate HTML files that can be viewed in any web browser.

The communication layer is responsible for ensuring that the system is always connected to some network. For that purpose, it may use the Netbook wireless capabilities or the connection with the PDA which has access to mobile networks, which nowadays cover almost all the inhabited areas and have considerable speeds for data transfer.

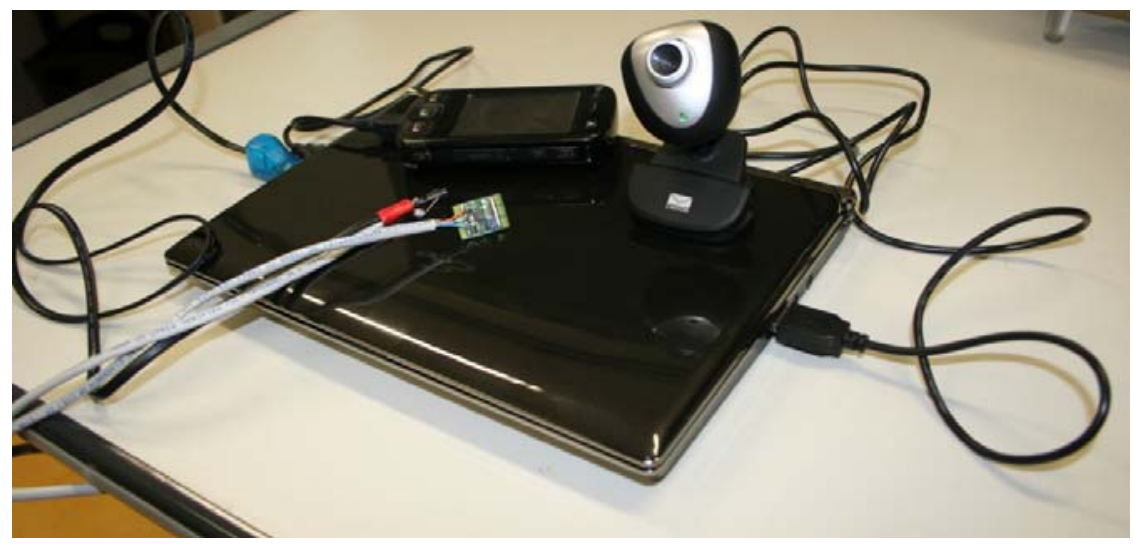

Fig. 5. The prototype of EMon with its components connected: a netbook, a PDA, a webcam and two sensors.

As for the services layer, its task is to provide support for the Web Services. In this first prototype of the system, only the data from the wireless webcam is provided via Web Service. To provide the services of the webcam the GlassFish application server is being used. The application developed consists of an online interface, accessible thru a web browser that, by means of the java media framework, enables to remotely control the camera (i.e. take pictures). When a picture is taken, it is visible on the web browser and automatically transferred, via Web Service, to a folder on the server. If the user intends to take a picture, he must also use the same interface and the picture is also transferred to the server so that he may later have access to it.

The prototype, as depicted here, is made of only a few devices so the functionalities are still limited (Figure 5). The architecture however, by being based on open and service-oriented technologies, allows for virtually any devices to be connected, ensuring that the prototype is highly expansible and multifaceted. 


\section{The Future of EMon and Similar Projects}

EMon has much to evolve in order to become what the authors envisioned: a device small enough to be comfortably carried by its user, nevertheless completely monitoring him and his surroundings. In order to achieve this vision, several issues have to be solved. In one hand, the devices in question must become smaller and more portable: it is, although their small size and weight, impracticable to go around carrying a netbook embedded in our clothes.

EMon will also be empowered with more sensors to enrich its features. One of the more important will be the ability to monitor the elder's vital signs in real time as they configure the most important health information one can have about an individual. Another important enhancement will be to add sensors for sensing the quality of the air and initiate actions for adapting this quality. This will allow to monitor people who are intolerant to some specific gases or particles with the objective to avoid respiratory conditions.

Concerning the web cam, we are currently only sending via Web Service still images. It is our desire to provide EMon with the ability to send live video when needed or to record video as well as audio. The webcam will also need to be replaced by a smaller camera. Another improvement would be to develop the system or at least the backbone of it in washable electronics so that the jacket could easily be washed by its user. At last, we will develop an intuitive integrated interface showing in real time all the information generated by the system, that can be accessed locally by the user in its handheld device or remotely by authorized personal of the VirtualECare platform.

The fields of application of projects similar to EMon are however much more extensive that just the healthcare sector. There are similar applications of the same technologies in the most different fields with the common objective of monitoring persons or their surroundings while on-the-move. As an example we can mention a chest belt being used by the USA military that is able to provide automatic ECG measurements [17] and that is now being applied to sports clothing, with the support of Adidas. Another good example is Ericsson Mobile Health, which intends to provide healthcare professionals with vital and objective information about the patients, allowing the assessment of their health status while on the move and avoiding unnecessary routine checkups, letting patients live more normal lives.

\section{Conclusion}

In this paper we have presented the EMon prototype. We integrated some different components in a common architecture with the aim of providing monitorization to seniors while on the move. If in one hand the device is still too big to be comfortably carried around and has little functionalities, in other hand we have proved that the concept is valid and feasible. In our tests we concluded that the GPS system is not very effective when used in some urban scenarios although it is very accurate when used in open air spaces, without nearby obstacles. To try to minimize this problem, we integrated a web cam with the objective of providing additional information about the location of the person. The implementation of the architecture presented revealed 
itself easy, mainly due to the experience this team gained in developing previous monitorization projects. It is our conviction that this new project constitutes a major improvement to the VirtualECare platform, and that the concept presented in this paper is the path to ensure the security and accompaniment of seniors while outside their environments.

\section{References}

1. Weil, D.: Population Aging. Department of Economics, Brown University and NBER (2006).

2. Turner, D., Giorno, C., Serres, A., Vourc'h, A., Richardson, P.: The Macroeconomic Implications of Ageing in a Global Context. OECD Economics Department Working Papers, No. 193, OECD Publishing (1998).

3. United Nations: World Population Ageing: 1950-2050. UN (2002).

4. Malmberg, A.: Industrial Geography: agglomeration and local milieu. In: Progress in Human Geography, vol. 20, 392-403 (1996).

5. Al-Hamad, A., Flowerdew, R., Hayes, L.: Migration of elderly people to join existing households: some evidence from the 1991 Household Sample of Anonymised Records. In: Environment and Planning A 29(7) 1243 - 1255 (1997).

6. Bahadori, S., Cesta, A., Iocchi, L., Leone, G., Nardi, D., Pecora, F., Rasconi, R., Scozzafava, L.: Towards Ambient Intelligence For The Domestic Care Of The Elderly. Ambient Intelligence, pp. 15-38, Springer (2005).

7. Novais, P., Costa, R., Carneiro, D., Machado, J., Lima, L., Neves, J.: Group Support in Collaborative Networks Organizations for Ambient Assisted Living. In: Oya, M., Uda, R., Yasunobu, C., (eds.) Towards Sustainable Society on Ubiquitous Networks. SpringerVerlag, Series: IFIP International Federation for Information Processing (2008).

8. Costa, R., Novais, P., Machado, J., Alberto, C., Neves, J.: Inter-organization Cooperation for Care of the Elderly. In: Wang, W., Li, Y, Duan, Z., Yan, L., Li, H., Yang, X., (Eds.) Integration and Innovation Orient to E-Society. Springer-Verlag, Series: IFIP International Federation for Information Processing, ISBN: 978-0-387-75493-2 (2007).

9. Havasi, F., Kiss, Á.: Ambient Assisted Living in Rural Areas: Vision and Pilot Application. In Constructing Ambient Intelligence, pp. 246-252 (2008).

10.Panek, P., Zagler, W.: A Living Lab for Ambient Assisted Living in the Municipality of Schwechat. In Computers Helping People with Special Needs, pp. 1008-1015 (2008).

11. García, O., Tapia, D., Saavedra, A., Alonso, R., García, I.: ALZ-MAS 2.0; A Distributed Approach for Alzheimer Health Care. 3rd Symposium of Ubiquitous Computing and Ambient Intelligence, pp. 76-85 (2008).

12.Carneiro, D., Costa, R., Novais, P., Machado, J., Neves, J.: Simulating and Monitoring Ambient Assisted Living. In: Proceedings of the ESM 2008 - The 22nd annual European Simulation and Modelling Conference (2008).

13.Carneiro, D., Novais, P., Costa, R. and Neves, J.: Case-Based Reasoning Decision Making in Ambient Assisted Living. In S. Omatu et al. (Eds.): IWANN 2009, Part II, SpringerVerlag LNCS 5518, pp. 787-794 (2009).

14.D'Amato, G., Liccardi, G., D'Amato, M., Cazzola, M.: Outdoor air pollution, climatic changes and allergic bronchial asthma. European Respiratory Journal, vol. 20. (2002).

15. Oberdörster, G.: Pulmonary effects of inhaled ultrafine particles. International Archives of Occupational and Environmental Health, vol. 74, pp. 1-8 (2000).

16.O.S.G.i: OSGi Service Platform, Release 3. IOS Press (2003).

17.National Defense Magazine, August 2008, Heart Monitoring for Soldiers on the Move, http://www.nationaldefensemagazine.org/archive/2007/August/Pages/TechTalk4893.aspx 